\title{
Chromatographic analysis of phytochemicals in the peel of Musa paradisiaca to synthesize silver nanoparticles
}

Análisis cromatográfico de fitoquímicos en la cáscara de Musa paradisiaca para sintetizar nanopartículas de plata

\section{María José Buendía-Otero (iD ${ }^{*}$, Deisy Julieth Jiménez-Corzo (iD)1, Zulia Isabel Caamaño De Ávila (iD)2, Juan B. Restrepo}

${ }^{1}$ Departamento de Ingeniería Química, Universidad del Atlántico. Carrera 43 \# 50 - 53. A. A. 1890. Barranquilla, Colombia.

${ }^{2}$ Departamento de Física, Universidad del Atlántico. Carrera 43 \# 50 - 53. A. A. 1890. Barranquilla, Colombia.

\section{CITE THIS ARTICLE AS:}

M. J. Buendía, D. J. Jiménez,

Z. I. Caamaño De Ávila and J.

B. Restrepo.

"Chromatographic analysis of phytochemicals in the peel of Musa Paradisiaca to synthesize silver nanoparticles", Revista

Facultad de Ingeniería

Universidad de Antioquia, no.

103, pp. 130-136, Apr-Jun

2022. [Online]. Available:

https:

//www.doi.org/10.17533/

udea.redin. 20210427

\section{ARTICLE INFO:}

Received: December 09, 2020 Accepted: April 21, 2021

Available online: May 21, 2021

\section{KEYWORDS:}

Biosynthesis; nanoparticles; musa paradisiaca;

chromatographic analysis

Biosíntesis; nanopartículas; musa paradisiaca; análisis cromatográfico

\begin{abstract}
This research work used Musa paradisiaca(banana) peels as a natural solvent, assorted with the precursor $\mathrm{AgNO}_{3}(10 \mathrm{mM})$ to perform the green synthesis of silver nanoparticles. The phytochemical components present in the Musa paradisiaca peel extracts were determined by gas chromatography coupled to a mass spectrometer (GC-MS), and it was possible to identify the compounds: 1.2 Ethanediol 160.0261 $\%)$ and 2.3 Butanediol (11.2\%); these -diols represent a highly reducing agent for metals, since they act as a solvent for the metal precursor behaving as a reducing agent, and facilitating the formation of nanoparticles. Likewise, the synthesized silver nanoparticles were subjected to a washing and drying treatment to be subsequently characterized by means of UV-Vis and XRD techniques, resulting in a wavelength of $411 \mathrm{~nm}$, which is characteristic of these metallic nanoparticles, and achieving the identification of the face-centered cubic structure ( $f c c$ ) of the metallic silver, with an average particle size of $21.8 \mathrm{~nm}$ according to the Debye-Scherrer equation.
\end{abstract}

RESUMEN: Este trabajo de investigación utilizó las cáscaras de Musa paradisiaca (banana) como un solvente natural, el cual fue puesto en contacto con el precursor $\mathrm{AgNO}_{3}(10 \mathrm{mM})$ para realizar la síntesis verde de nanopartículas de plata. Los componentes fitoquímicos presentes en los extractos de la cáscara de Musa Paradisiaca se determinaron por cromatografía de gases acoplada a un espectrómetro de masas (GC-MS), y se lograron identificar los compuestos: 1,2 Etanodiol (60,0261\%) y 2,3 Butanodiol (11,2\%); estos -dioles representan un agente altamente reductor para metales, ya que actúan como solvente para el precursor metálico comportándose como agente reductor, y facilitando la formación de nanopartículas. Asimismo, las nanopartículas de plata sintetizadas se sometieron a un tratamiento de lavado y secado para ser posteriormente caracterizadas mediante las técnicas UV-Vis y DRX, dando como resultado una longitud de onda de $411 \mathrm{~nm}$, la cual es característica de estas nanopartículas metálicas, y logrando identificar la estructura cúbica centrada en las caras ( $f c c$ ) de la plata metálica, con un tamaño promedio de partícula de 21,8 nm de acuerdo con la ecuación de Debye-Scherrer.

\section{Introduction}

The interest in chemical species at the nanoscale is one of the most important scientific and biomedical research fields, mainly due to various new properties and potential

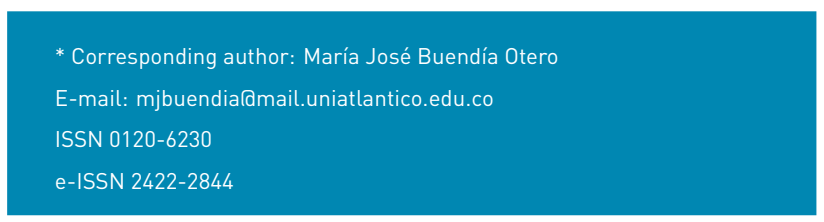

applications that can be developed in different areas. At this scale, there are metallic nanoparticles, which present interesting biological, optical, magnetic, electronic, and catalytic properties [1].

Due to the valuable antimicrobial condition of silver nanoparticles (AgNPs), they are significant to the medical and chemical industries. Some studies show that silver nanoparticles have a very strong bactericidal effect in 
sizes between 1 and $10 \mathrm{~nm}$. There are different ways to synthesize AgNPs using physical and chemical methods, but recent research has focused on alternative methods such as biosynthesis or green synthesis, due to a growing need for environmentally friendly synthesis methods using reducing and finishing agents [2].

There are numerous plant extracts used in the synthesis of AgNPs, such as Aloe vera (aloe vera), Azadirachta indica (Indian lilac), Camellia sinensis (tea plant), Carica papaya (papaya), Capsicum annum (chili bell pepper), Coriandrum sativeem (coriander), natural rubber, Tamarindus indica (tamarind), Musa paradisiaca (banana), which have been successfully tested for the formation of silver nanoparticles [1]. This makes Musa paradisiaca attractive to be implemented in this study, because Colombia is one of the major players in the international banana trade, occupying the fourth place with an equivalent of $9 \%$ of the total volume of banana exports worldwide [3]. Furthermore, it is considered that banana peel can be a potential source of antioxidant and antimicrobial substances, as well as phytochemical compounds with activity against free radicals. This is why it is necessary to take advantage of these residues, being banana peels a classic example of natural material available in abundance, are usually discarded [4].

Previous studies demonstrate the effectiveness of Musa paradisiaca peel in the synthesis of gold nanoparticles, being this extract simple, non-toxic, and environmentally friendly. These nanoparticles showed sizes of $300 \mathrm{~nm}$ and efficient antimicrobial activity towards most of the tested fungal and bacterial cultures [4].

The composition and concentration of the nanoparticles are determined by Ultraviolet-visible spectroscopy, X-ray diffraction, chromatography, and some other techniques [5]. Its importance lies in the fact that the properties of metallic nanoparticles depend on their size and shape. Therefore, it is necessary to monitor their synthesis, which will be reflected in the characterization [6].

To prepare silver nanoparticles, chemical reduction methods are the most used. Generally, the synthesis of nanoparticles in colloidal suspensions by chemical methods requires the following components: metallic precursors, reducing, and stabilizing agents. The metal precursor is composed of silver salt, from which raw materials can be obtained, and then the nanoparticles are formed, as shown in Figure 1. From the dissociation of the salt in the solvent, ionic silver can be obtained. The next step is to reduce the silver ion to a state of zero valency, which is achieved in the presence of a reducing agent, which can basically yield electrons [7]. This can be

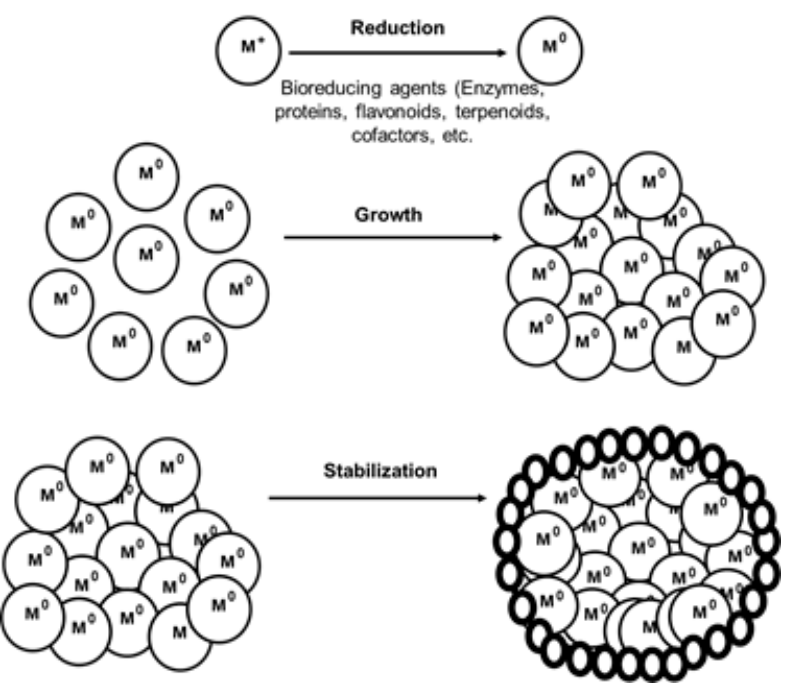

Figure 1 Nanoparticle synthesis mechanism [7]

expressed by the following chemical Equation (1):

$$
A g^{+}+R e d \rightarrow A g^{0}+R e^{+}
$$

Where: Red: Form of the unreacted reducing agent.

$\mathrm{Re}+$ : Reducing agent form in oxidation state.

Finally, the neutral silver atoms aggregate and form groups. The objective in this phase is that the size of these complexes is a maximum of $100 \mathrm{~nm}$, the limit size to be considered as nanoparticles; in this phasee, a stabilizing agent is used to prevent agglomerations beyond this size [7].

In this work, the synthesis of AgNPs was developed implementing green chemistry, which is based on reduction reactions of metallic silver salts, using a natural solvent as a reducing agent. In order to evidence the composition and concentration of the synthesized nanoparticles, UV-Visible and XRD characterization techniques were implemented. Likewise, to determine the influence of the extract on the formation of AgNPs, the technique of gas chromatography coupled to a mass spectrophotometer was used.

\section{Methodology}

\subsection{Synthesis of silver nanoparticles}

Twenty-six Musa Paradisiaca shells (dry weight 1580 g) were collected in order to acquire a natural extract that favors the process of silver nitrate reduction and thus synthesizes the nanoparticles. The pre-treatment for the banana peels consisted of cutting and washing them thoroughly with distilled water at $90{ }^{\circ} \mathrm{C}$ for $30 \mathrm{~min}$. Subsequently, the selected $(1580 \mathrm{~g})$ banana peels were crushed with mortar and pestle and dissolved in 1600 
$\mathrm{ml}$ of distilled water, following the 1:1 ratio. Finally, the resulting extract was filtered through a clean cloth and stored in glass containers previously washed with distilled water.

The synthesis of silver nanoparticles was carried out by reducing a precursor salt, silver nitrate $\left(\mathrm{AgNO}_{3}\right)$, using the previously prepared banana peel extract as a reducing agent, in order to avoid the implementation of organic solvents that produce undesirable products as pollutants.

To carry out this synthesis, a $100 \mathrm{mM}$ silver nitrate stock solution was originally prepared by weighing 1.6614 $\mathrm{g}$ of silver nitrate and diluting it in $100 \mathrm{ml}$ of distilled water. In due course, $25 \mathrm{ml}$ of the stock solution were extracted and placed in a $250 \mathrm{ml}$ balloon filled with distilled water lapproximately $225 \mathrm{ml}$ ), resulting in a $10 \mathrm{mM}$ silver nitrate solution; this procedure was performed in triplicate.

The procedure of the synthesis of the AgNPs consisted of mixing the extract $(533 \mathrm{ml})$ of the banana peels with $250 \mathrm{ml}$ solution of silver nitrate $10 \mathrm{mM}$; this procedure was performed in triplicate. This reaction was initially performed at room temperature for 10 minutes; therefore, the temperature of the solution was increased to $65^{\circ} \mathrm{C}$ for 50 minutes, and the solution was constantly stirred at 500 rpm.

The synthesized nanoparticles were suspended by adding $2 \mathrm{M}$ sodium hydroxide until they reached a $\mathrm{pH}$ of 10 , so that they have good colloidal stability. Finally, the nanoparticles were separated from the reaction medium by centrifugation at $3500 \mathrm{rpm}$ for $10 \mathrm{~min}$. This nanoparticle residue obtained was first washed with ethanol and then with distilled water; in each wash, it was centrifuged at $3500 \mathrm{rpm}$ for 10 minutes. The obtained washed residue was deposited in an oven at $100^{\circ} \mathrm{C}$ for 6 hours, to evaporate any presence of water and ethanol, resulting in a thin layer of nanoparticles, as can be seen in Figure 2.

\subsection{Characterization of silver nanoparticles}

\section{UV-VIS spectroscopy}

In order to determine if the silver nanoparticles were formed, a UV-Visible spectroscopy was used with a BK-UV1900 model equipment. In this technique, the samples were prepared by diluting a drop of each solution of extract and silver nanoparticles in different test tubes with $2 \mathrm{ml}$ of distilled water, then the new solutions were shaken in a vortex until obtaining optically transparent solutions, thus concluding the test.

In the case of the analyzed sample of silver nanoparticles, special care was taken because if the nanoparticles were

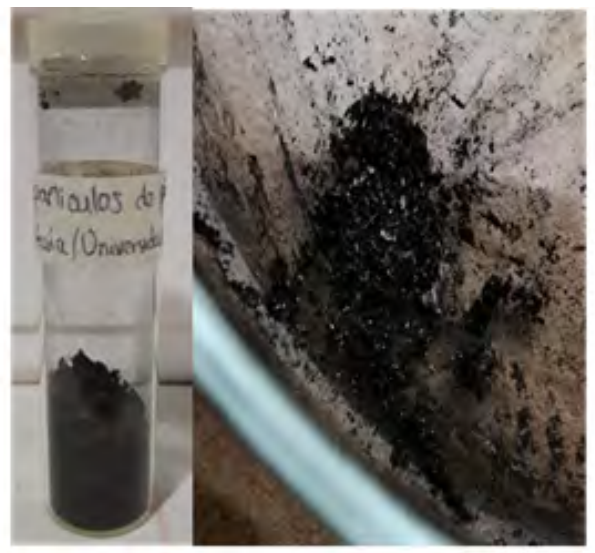

Figure 2 Silver nanoparticles synthesized using Musa paradisiaca extract as a salt reducing agent $\mathrm{AgNO}_{3}$

not in suspension, the spectrometer would not read the peak. Once the samples were prepared, a sweep was carried out in a $300-500 \mathrm{~nm}$ range, and the absorbance peak was found for each sample.

\section{X-ray diffraction}

The diffractometer used for the characterization of the silver nanoparticle sample was an XPert PANalytical Empyrean Series II - Alpha1, Model 2012 branded Malvern Panalytical. To perform the analysis, $2 \mathrm{~g}$ of silver powder nanoparticles were placed in the sample holder of the equipment, under the following established conditions of $40 \mathrm{kV}$ and $40 \mathrm{~mA}$, a step size of $0.05^{\circ}$ and a step time of 50 sec. Therefore, a scanning angular speed of $0.06 \% \mathrm{~min}$ was used. The scanning angle $2 \theta$ ranged from 5 to $60^{\circ}$.

\section{Gas-mass chromatography}

The composition of the phytochemicals present in Musa Paradisiaca extract was obtained by direct injection of $1 \mu \mathrm{l}$ of Musa Paradisiaca extract in the mobile phase, using an Agilent Gas Chromatograph with Selective Mass Detector (GC-MS), and with the model $6890 \mathrm{~N}$. The selective mass detector is Agilent's brand, model 5973N, and a column DB-1MSInyector: Split/Splitless.

The column was located inside an oven with a temperature program; in the programming of the oven temperature, a starting temperature of $45^{\circ} \mathrm{C}$ was used and held for 15 $\mathrm{min}$, then the temperature was increased to $60^{\circ} \mathrm{C}$ at a rate of $5^{\circ} \mathrm{C} / \mathrm{min}$, and held for $10 \mathrm{~min}$; finally, the temperature was increased at a rate of $2^{\circ} \mathrm{C} / \mathrm{min}$ to $70^{\circ} \mathrm{C}$ and held for $13 \mathrm{~min}$ for a total of $38 \mathrm{~min}$ run.

\section{Results and discussion}




\subsection{Synthesis of silver nanoparticles}

After obtaining the natural solvent from banana peels (Musa paradisiaca), it was used to produce the silver nanoparticles with $10 \mathrm{mM}$ concentration. During the synthesis of the nanoparticles, a color change from transparent to yellow-brown was observed, being effective in the formation of silver nanoparticles [8]. This synthesis was influenced by the temperature and reaction time, for which the values of $65^{\circ} \mathrm{C}$ and 50 min were chosen, based on studies carried out by other researchers [2], showing the effect of the reaction temperature for a range of 30 to $100^{\circ} \mathrm{C}$, and obtaining the best results for temperatures above $60^{\circ} \mathrm{C}$, since when this increases, the reagents are consumed quickly, leading to the formation of smaller nanoparticles. With respect to the reaction time, this study evidenced that the intensity of the brown color was directly proportional to the incubation time of the reaction mixture and the constant stirring that guarantees the homogeneity of the solution, so that the reduction of silver ions is completed around $50 \mathrm{~min}$.

\subsection{Phytochemical components in the extract of musa paradisiaca}

A gas chromatograph connected to a mass spectrometer (GC/MS) was used to determine the phytochemical components of the Musa paradisiaca extract. Some of the compounds that promote the reduction of metal salts during synthesis can be identified by this type of analysis. The chromatogram obtained from this measurement is shown in Figure 3, and Table 1 shows a list of the main components detected.

The chromatographic analysis showed mainly the presence of 1.2 Ethanediol (60.0261\%) and 2.3 Butanediol (11.2\%), which promote the reduction of silver ions, favoring the formation of nanoparticles [9]. These diols act as a reducing agent for metals, since they behave as a solvent for the metallic precursor and show a higher dielectric constant, which makes them better solvents, presenting a high boiling point [9]. The properties of these compounds allow metallic materials to be transformed into their basic state of electronegativity, which is equivalent to nanoscale and makes free ions attract each other and form nanoparticles. On the other hand, the acetic acid present in $1.7376 \%$ favors the stabilization of the AgNPs by acting as a primary surfactant during the nucleation stage of this nanomaterial [10]. This organic acid is essentially found in fruits, and given its structure, it can be coupled to metallic nanoparticles through carboxylic bonds (COO-) and limit the growth of the material's size.

On the other hand, Table 1 also shows compounds that have active organic functional groups $(-\mathrm{OH},-\mathrm{NH} 2$, $-\mathrm{CHO}$ ) of phytochemicals (amino acids, proteins, flavonoids and terpenoids) that were oxidized by reducing the $\mathrm{Ag}+$ ion to AgNPs. AgNPs surfaces were protected by the phytochemicals, making them promising candidates for various applications. Therefore, phytochemicals played a double role as reducing and stabilizing agents. The stretching vibrations of various organic groups $1-\mathrm{OH}$, $-\mathrm{NH} 2,-\mathrm{CHO}$, and phenolic) of phytochemicals disappeared or changed due to the oxidation of these groups by the $\mathrm{Ag}$ + ion [11].

\subsection{Characterization of silver nanoparticles}

\section{UV-visible spectroscopy}

Figure 4 shows the results obtained on the prepared sample of $10 \mathrm{mM}$ at a pH of 10 . Soriano et al. determined that the formation of silver nanoparticles is attributed to the appearance of a surface plasmon resonance peak, when these were in a wavelength range of 400 to $450 \mathrm{~nm}$ [12]. Therefore, in this image, the appearance of silver nanoparticles is confirmed since a maximum absorption peak was detected when it reached a wavelength of 411 $\mathrm{nm}$.

In the spectrum, a single band with a maximum absorption peak can be observed, and the formation of silver nanoparticles with sizes between 14 and $35 \mathrm{~nm}$ can be estimated. This is stated based on the spectral characteristics of silver nanoparticles reported in Table 2.

The maximum wavelength of absorption in the plasmon of a given solvent can be used to indicate particle size. This study shows silver nanoparticles that produced a wavelength spectrum equal to $400 \mathrm{~nm}$, which is corroborated using transmission electron microscopy (TEM) and size distribution, which showed that the particles become larger as the plasmon peak shifts to longer wavelengths and broadens [13].

\section{X-ray Diffraction (XRD)}

In order to determine the crystalline phase corresponding to silver, XRD analyses for silver nanoparticles were performed according to its characteristic face-centered cubic structure [14]. Figure 5 describes the diffraction pattern that indicates the crystalline nature of the silver nanoparticles synthesized by Musa paradisiaca aqueous extract, which corresponds to the face-centered cubic ( $f c c$ ). The diffractogram shows three different diffraction peaks observed in the $2 \theta$ range of $30-70^{\circ}$ (with values for $2 \theta=38,45,65)$. This is associated with planes $\left(\begin{array}{lll}1 & 1 & 1\end{array}\right)$, $\left(\begin{array}{lll}2 & 0 & 0\end{array}\right)$ and $\left(\begin{array}{lll}2 & 2 & 0\end{array}\right)$ [15], reflections of the face-centered cubic phase of the metallic silver, consistent with the XRD patterns shown in previous reports on microstructures.

According to the diffractogram, it can be observed that 


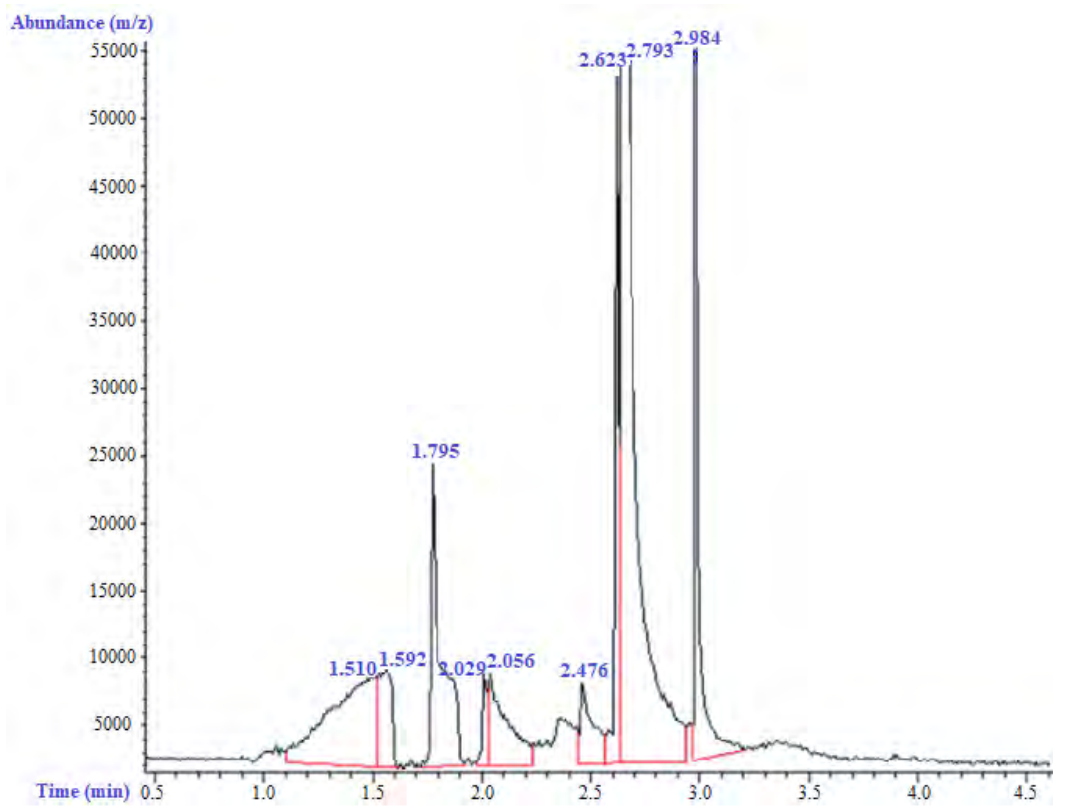

Figure 3 Chromatogram of the measurement of the Musa paradisiaca extract

Table 1 List of the main components of the analysis

\begin{tabular}{cclcc}
\hline PK & AREA Pct & Library/ID & Ref & Qual \\
\hline $\mathbf{1}$ & 0.2394 & Acetaldehyde & 69 & 4 \\
$\mathbf{8}$ & 0.2519 & 2-Propanamine, 1-Methoxy & 2167 & 9 \\
$\mathbf{9}$ & 0.2819 & Ethion, Fluor & 73 & 4 \\
$\mathbf{1 0}$ & 8.0442 & Propane & 75 & 9 \\
$\mathbf{1 1}$ & 2.6926 & 3-buten-1-ol, 3-methyl- & 1760 & 10 \\
$\mathbf{1 2}$ & 6.1009 & 1,2-ethanediol & 314 & 16 \\
$\mathbf{1 3}$ & 0.7085 & Silane, methyl & 102 & 9 \\
$\mathbf{1 4}$ & 3.2335 & Dimethylamine & 85 & 9 \\
$\mathbf{1 5}$ & 1.5663 & Dimethylamine & 84 & 9 \\
$\mathbf{1 6}$ & 1.7376 & Acetic acid, formic acid anhydride & 1926 & 43 \\
$\mathbf{1 7}$ & 4 & Silane diol, dimethyl- & 2353 & 23 \\
$\mathbf{1 8}$ & 60.0261 & 1,2-ethanediol & 314 & 86 \\
$\mathbf{1 9}$ & 11.2 & 2,3-butanediol & 110787 & 91 \\
\hline
\end{tabular}

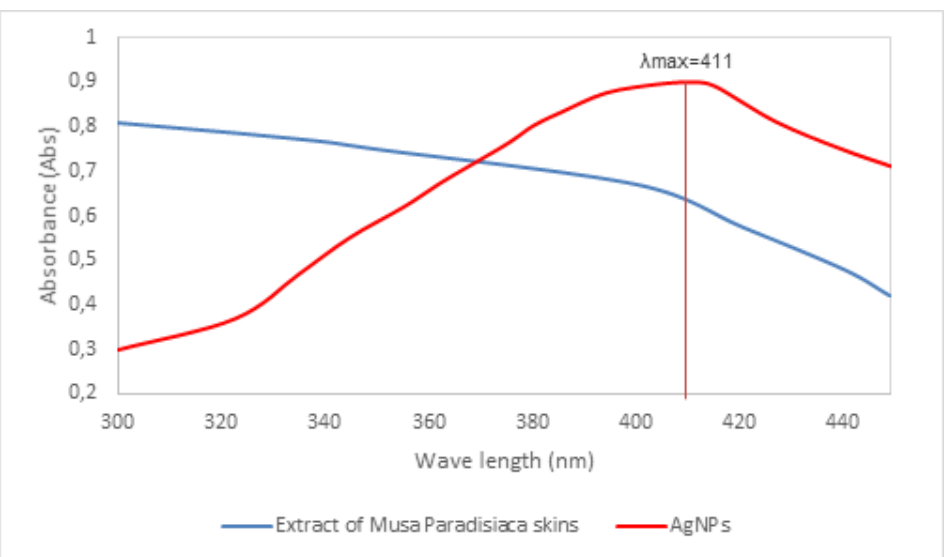

Figure 4 UV-Vis spectroscopy of aqueous suspensions of silver nanoparticles at $10 \mathrm{mM}, \mathrm{pH} 10$ and extract of Musa paradisiaca 


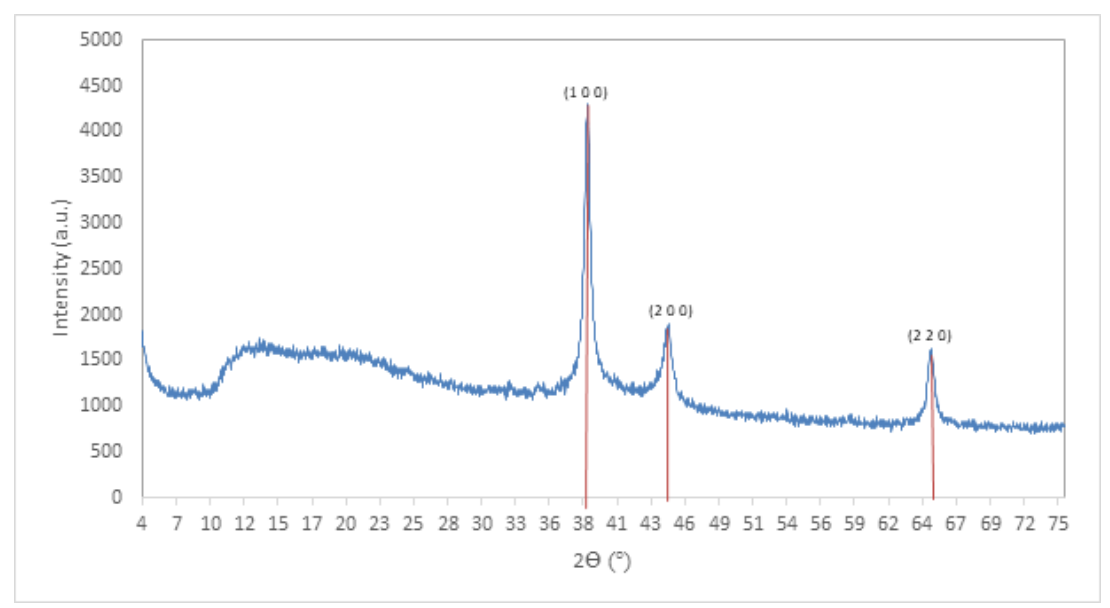

Figure 5 Diffractogram of the synthesized silver nanoparticles

Table 2 Particle size and spectral characteristics of silver nanoparticles [13]

\begin{tabular}{cc}
\hline Nanoparticle size $(\mathrm{nm})$ & $\boldsymbol{\lambda} \max (\mathrm{nm})$ \\
\hline $\mathbf{1 0 - 1 4}$ & $395-405$ \\
$\mathbf{3 5 - 4 0}$ & 420 \\
$\mathbf{6 0 - 8 0}$ & 438 \\
\hline
\end{tabular}

the diffraction peak located in the angular position at $38^{\circ}$ presented a higher intensity compared to the peaks at $45^{\circ}$ and $65^{\circ}$, indicating that the silver nanoparticles present a greater arrangement of their atoms in 111 planes, and based on what was reported by Pal and collaborators [12], a major reactivity of the silver nanoparticles is expected, since it is favored by planes with a high density of atoms such as the 111 plane.

\section{Particle size calculation}

The average crystal size of each sample was determined using the Debye-Scherrer equation, assuming that the crystal lattice is free of deformation and the crystals generally predominate in the sample, by the following equation (Equation (2)) [17]:

$$
d=\frac{k * \lambda}{F W H M * \operatorname{Cos} \theta}
$$

Where: $d$ is the average crystallite size, $k$ is the shape factor of the crystal, and its value is $0.9, \lambda$ is the wavelength of the radiation used $(\lambda \mathrm{Cu}), \theta$ is the position of the diffraction peak, and FWHM is the Full Width at Half Maximum of the sample's diffraction peak.

Using the OriginPro 2020b program, the width at the mean height of the highest intensity peak was determined by multiple peak adjustments and obtained in Table 3, from which the mean particle size for the silver nanoparticles was determined.
Table 3 Peak diffraction with higher intensity and respective FWHM

\begin{tabular}{ccc}
\hline Angle (日) & FWHM & $\mathbf{d}$ (nm) \\
$\mathbf{3 8 . 3 9 3 5 6}$ & 0.40324 & 21.8049792 \\
\hline
\end{tabular}

The value of the FWHM in radians, together with the wavelength of the $\mathrm{X}$-ray emission for $\mathrm{Cu}-\mathrm{K} \alpha$ with a value of $1.54178 \times 10^{-10} \mathrm{~m}$, allows obtaining, as a result, the average particle size calculated for the peak of diffraction with the highest intensity, giving a value of $21.8 \mathrm{~nm}$, by means of the Debye-Scherrer equation.

This result confirms the above; according to the data obtained by UV-Visible spectroscopy, it was inferred using Table 2 that the particle size for an absorbance peak at $411 \mathrm{~nm}$ should be between 14 and $35 \mathrm{~nm}$.

From the XRD spectrum, studies have been developed that show the nature of silver nanoparticles. The XRD pattern showed four intense peaks ranging from $20^{\circ}$ to $80^{\circ}$, with diffraction peaks in the following values: $38.45,44.48$, 64.69, and 77.62 correspond to the planes for silver (111), (200), (220), and (311), respectively, which illustrates the complete reduction of $\mathrm{AgNO}_{3}$ by the use of an aqueous extract of $\mathrm{C}$. Vulgaris. The Debye-Scherrer formula was used to evaluate the mean particle size, giving a value of $18.94 \mathrm{~nm}$, because, in the XRD pattern, the maximum amplitude is proportional to the mean crystal size of the material. These results were compared by means of TEM analysis, which gave an average value of approximately 20 $\mathrm{nm}[18]$.

Other researchers performed X-ray diffraction (XRD) analysis of a sample of silver nanoparticles synthesized using green chemistry [19]. In this study, the XRD pattern 
was analyzed to determine the maximum intensity, position, and mean height width (FWHM). The FWHM was used in the Debye-Scherrer formula to find the mean particle size, resulting in a size of $16.6 \mathrm{~nm}$. Bragg reflections were also observed corresponding to the set of planes of the network related to the face-centered cubic crystalline structure ( $f(c)$. The average size of the silver nanoparticles given in the TEM analysis is approximately $16 \mathrm{~nm}$ and with spherical morphology. The above is consistent with the particle size found in the present investigation, and it can also be noted that for these studies, the error between the size found by TEM and the Debye-Scherrer equation does not exceed $6 \%$.

\section{Conclusions}

Using the extract of Musa paradisiaca peel (banana) as a natural solvent, the synthesis of silver nanoparticles was carried out through an environmentally friendly method, compared to conventional chemical methods. This method is characterized by its easy operation and low cost, contributing to the environmental richness achieved when no toxic compounds are used in the synthesis stage.

The synthesis of the silver nanoparticles was demonstrated using characterization techniques (UV-Vis and XRD). These tests showed the existence of the silver nanoparticles obtained in the synthesis, since by UV-Vis the maximum absorbance peak was observed, of $411 \mathrm{~nm}$, in the range of 400 to $450 \mathrm{~nm}$. By XRD, it was evidenced the face-centered cubic crystalline phase of the silver, with diffraction peaks positions in 2theta of $38^{\circ}, 45^{\circ}$, and $65^{\circ}$, and it was determined that it has an average particle size of $21.8 \mathrm{~nm}$ by means of the Debye-Scherrer equation. These results correspond to those obtained with the silver nanoparticles described in other studies.

This study shows that at room temperature, the phytochemical components present in the extract of Musa paradisiaca's peels can promote the formation of silver nanoparticles; such analysis mainly indicated the presence of these compounds: 1.2 Ethanediol 160.0261 $\%$ ) and 2.3 Butanediol (11.2 \%), which facilitate the reduction of silver ions, contributing to the formation of nanoparticles, and acetic acid (1.7376 \%) which helps to stabilize the AgNPs by behaving as a primary surfactant during the nucleation stage of this nanomaterial.

\section{Declaration of competing interest}

We declare that we have no significant competing interests, including financial or non-financial, professional, or personal interests interfering with the full and objective presentation of the work described in this manuscript.

\section{Acknowledgements}

The authors want to thank all the contributors: The University "Universidad del Atlantico", for providing us the necessary resources that facilitated the experimentation. A special acknowledgment to PhD. Adriana Herrera for her advice and confidence in providing us with a space with total freedom to use the materials and equipment in the laboratory of Materials Science and Biotechnology at the University of Cartagena. Also, we want to thank Eng. Ricardo Solano, for the accompaniment in the synthesis of the samples and for his help in the interpretation of some results of this research work.

\section{References}

[1] V. S. Kotakadi and et al., "Biofabrication of silver nanoparticles using andrographis paniculata," European Journal of Medicinal Chemistry, vol. 73, Feb. 12, 2014. [Online]. Available: https: //doi.org/10.1016/j.ejmech.2013.12.004

[2] H. Ibrahim, "Green synthesis and characterization of silver nanoparticles using banana peel extract and their antimicrobial activity against representative microorganisms," Journal of Radiation Research and Applied Sciences, vol. 8, no. 3, 2015. [Online]. Available: https://doi.org/10.1016/j.jrras.2015.01.007

[3] (2020) Análisis del mercado del banano: resultados preliminares 2019, 2020. Organización de las Naciones Unidas para la Alimentación y la Agricultura (FAO). [Online]. Available: http://www.fao.org/3/ca7567es/CA7567ES.pdf

[4] A. Bankar, B. Joshi, A. R. Kumar, and S. Zinjarde, "Banana peel extract mediated synthesis of gold nanoparticles," Colloids and Surfaces B: Biointerfaces, vol. 80, no. 1, Oct. 1, 2010. [Online]. Available: https://doi.org/10.1016/j.colsurfb.2010.05.029

[5] M. V. Vázquez and L. Blandón, "Antimicrobial performance of electrochemically synthesized silver nanoparticles," Cuaderno Activa, vol. 6, 2014. [Online]. Available: https://ojs.tdea.edu.co/ index.php/cuadernoactiva/article/view/219

[6] G. Nam, S. Rangasamy, B. Purushothaman, and J. M. Song, "The application of bactericidal silver nanoparticles in wound treatment. nanomaterials and nanotechnology," College of Pharmacy, Seoul National University, Seoul, South Korea, vol. 5, 2015. [Online]. Available: https://doi.org/10.5772\%2F60918

[7] C. A. Pérez, "Synthesis of silver nanoparticles using plant extracts," Undergraduated. Degree work, Escuela de ingeniería de Antioquia, Envigado, Antioquia, 2014.

[8] H. G. Ganchozo and R. A. Luna, "Obtención de un nanocompuesto estructurado por nanocelulosa y dopado con nanopartículas de plata (agnps) con actividad antibacterial y cicatrizante, utilizando como materia prima los residuos de banano: raquis y cascara (musa acuminata)," Bachelor thesis, Universidad de Guayaquil, Facultad de Ingeniería Química, Guayaquil, Ecuador, 2018. [Online]. Available: http://repositorio.ug.edu.ec/handle/redug/35406

[9] J. C. Serge. (2016) Magnetic structures of $2 d$ and $3 d$ nanoparticles: properties and applications. Pan Stanford Publishing. [Online]. Available: https://n9.cl/3gry

[10] M. Mokhtari, M. Saban, and R. E. Gaynor, "Carboxylic acid stabilized silver nanoparticles and process for producing same," U.S. Patent US 8.460,584 B2, Jun. 11, 2015. [Online]. Available: https://patents.google.com/patent/US8460584B2/en

[11] J. R. Koduru, "Phytochemical-assisted synthetic approaches for silver nanoparticles antimicrobial applications: a review," Advances in Colloid and Interface Science, vol. 256, Jun. 2018. [Online]. Available: https://doi.org/10.1016/j.cis.2018.03.001

[12] F. Soriano and G. Morales, "Incorporation of silver nanoparticles in high impact polystyrene: Effect on polymerization kinetics 
and morphological structure," in Polymer Engineering \& Science. Revista Iberoamericana de Polímeros, 2011, pp. 116-124. [Online]. Available: https://doi.org/10.1002/pen.21978

[13] M. P. Hernandez, "Síntesis de nanopartículas de plata biológicamente asistida con opuntia sp. y su incorporación en membranas poliméricas nanofibrosas," M.S. thesis, Centro de investigación en química aplicada, Saltillo, Mexico, 2013.

[14] S. A. Ovalle, C. Blanco, and M. Y. Combariza, "In situ synthesis of silver nanoparticles on fique fibres," Revista Colombiana de Química, vol. 42, no. 1, 2013. [Online]. Available: http://www.scielo.org.co/ scielo.php?script=sci_arttext\&pid=S0120-28042013000100004

[15] K. Ponsanti, B. Tangnorawich, N. Ngernyuang, and C. Pechyen, "A flower shape-green synthesis and characterization of silver nanoparticles (agnps) with different starch as a reducing agent," Journal of materials Research and Technology, vol. 9, no. 5, 2020. [Online]. Available: https://doi.org/10.1016/j.jmrt.2020.07.077

[16] K. Jemal, B. V. Sandeep, and S. Pola, "Synthesis, characterization, and evaluation of the antibacterial activity of allophylus serratus leaf and leaf derived callus extracts mediated silver nanoparticles," Journal of Nanomaterials, 2017. [Online]. Available: https://doi.org/ 10.1155/2017/4213275

[17] M. Rabiei and et al., "Comparing methods for calculating nano crystal size of natural hydroxyapatite using x-ray diffraction," Journal of Nanomaterials, vol. 10, no. 9, 2020. [Online]. Available: https://doi.org/10.3390/nano10091627

[18] J. Annamalai and T. Nallamuthu, "Green synthesis of silver nanoparticles: characterization and determination of antibacterial potency," Applied nanoscience, vol. 6, no. 2, Feb. 2016. [Online]. Available: https://doi.org/10.1007/s13204-015-0426-6

[19] A. Saxena, R. M. Tripathi, F. Zafar, and P. Singhc, "Green synthesis of silver nanoparticles using aqueous solution of ficus benghalensis leaf extract and characterization of their antibacterial activity," Materials Letters, vol. 67, no. 1, Jan. 15, 2012. [Online]. Available: https://doi.org/10.1016/j.matlet.2011.09.038 